\title{
Synthesis and Characterization of Gallium Nitride Powders from a Gallium(III) Sulfate Salt in Flowing Ammonia
}

\author{
Woo-Sik Jung ${ }^{\dagger}$ \\ School of Chemical Engineering and Technology, College of Engineering, Yeungnam University, Gyongsan 712-749, Korea \\ (Received September 16, 2003; Accepted October 11, 2003)
}

\begin{abstract}
Gallium Nitride (GaN) powders were synthesized by calcining a gallium(III) sulfate salt in flowing ammonia in the temperature range $500-1100^{\circ} \mathrm{C}$. The process of conversion of the salt to GaN was monitored by X-Ray Diffraction (XRD). The salt decomposed to $\gamma-\mathrm{Ga}_{2} \mathrm{O}_{3}$ and then converted to $\mathrm{GaN}$ without $\gamma-\beta \mathrm{Ga}_{2} \mathrm{O}_{3}$ phase transition. Variations in XRD patterns and weight loss of samples with temperature indicate that the conversion of $\gamma-\mathrm{Ga}_{2} \mathrm{O}_{3}$ to $\mathrm{GaN}$ does not proceed through $\mathrm{Ga}_{2} \mathrm{O}$ but stepwise via amorphous gallium oxynitride $\left(\mathrm{GaO}_{\mathrm{x}} \mathrm{N}_{\mathrm{y}}\right)$ as intermediates. Room-temperature photoluminescence spectra of GaN powders obtained showed the emission peak at $363 \mathrm{~nm}$ and no yellow band.
\end{abstract}

Key words : Gallium nitride, Gallium(III) sulfate, Powders, Gallium oxynitride, Photoluminescence

\section{Introduction}

G allium Nitride $(\mathrm{GaN})$ has a wide, direct band gap (3.4 $\mathrm{eV}$ at $300 \mathrm{~K}$ ) and is potentially useful to blue and ultraviolet light emission and high-temperature, high powder electronic devices. ${ }^{1)}$ The technology for growing high-quality $\mathrm{GaN}$ film on foreign substrates has been progressing in recent decades. Sapphire is the most widely used substrate for the thin-film growth of GaN. However, there exists severe mismatch both in lattice parameters and thermal expansion coefficients. Such a large mismatch induces stresses in the first few layers of GaN grown on sapphire. A trend for the future is, therefore, the development of $\mathrm{GaN}$ substrates for homoepitaxy by fabricating GaN bulk single crystals and wafers. Sublimation ${ }^{2)}$ and high-pressure solution methods ${ }^{3)}$ are considered for crystal growth of GaN. The methods demand the availability of well-characterized GaN powder source with high purity and single phase. Bulk GaN powders were prepared by reaction of ammonia with gallium metal or $\mathrm{Ga}_{2} \mathrm{O}_{3}{ }^{4)}$ and gallium oxyhydroxide $(\mathrm{GaOOH})$ as a $\mathrm{Ga}$ source. ${ }^{5}$ )

In this report we synthesize $\mathrm{GaN}$ powders using a gallium(III) sulfate salt, which is one of readily available $\mathrm{Ga}$ sources. The process of conversion of the salt to GaN was monitored by X-Ray Diffraction (XRD) and GaN powders obtained were characterized. The results are compared with those obtained with a gallium(III) nitrate salt. ${ }^{6)}$

\footnotetext{
Corresponding author: Woo-Sik Jung

E-mail : wsjung @yu.ac.kr

Tel : +82-53-810-2528 Fax : +82-53-814-8790
}

\section{Experimental}

The precursor material $\mathrm{Ga}_{2}\left(\mathrm{SO}_{4}\right)_{3} \cdot \mathrm{xH}_{2} \mathrm{O}$ (Kojundo Chemical Lab Co., 99.99\%) was used without further purification. GaN powders were synthesized by calcining the salt powders in an alumina crucible under a flow of ammonia (Showadenko Co., 99.999\%) in the temperature range 500$1100^{\circ} \mathrm{C}$ for $3 \mathrm{~h}$. The flow rate of ammonia was $50 \mathrm{ml} \mathrm{min}$. The samples were weighed before and after calcination. The conversion of the salt to GaN was monitored by XRD (Rigaku DMX-2500 diffractometer with $\mathrm{Cu}-\mathrm{K} \alpha$ radiation operating at $40 \mathrm{kV}$ and $100 \mathrm{~mA}$ ). The morphology of GaN products was investigated by Scanning Electron Microscopy (SEM, Hitachi S-4100). Room-temperature photoluminescence (PL) measurements of GaN powders obtained were carried out by using a He-Cd laser (excitation wavelength = $325 \mathrm{~nm})$.

\section{Results and Discussion}

Fig. 1 shows XRD patterns of samples synthesized by calcining a gallium(III) sulfate salt at different reaction temperatures for $3 \mathrm{~h}$. The sample calcined at $600^{\circ} \mathrm{C}$ is identified as $\gamma-\mathrm{Ga}_{2} \mathrm{O}_{3}{ }^{7}{ }^{7}$ In the sample calcined at $700^{\circ} \mathrm{C}$ weak diffraction peaks to assigned to $\mathrm{GaN}$ are detected together with those assigned to $\gamma-\mathrm{Ga}_{2} \mathrm{O}_{3}$. The temperature $\left(700^{\circ} \mathrm{C}\right)$ at which the diffraction peaks of $\mathrm{GaN}$ is first observed is the same as that for the case of gallium(III) nitrate. ${ }^{6)}$ With increasing the reaction temperature the peaks assigned to $\gamma$ $\mathrm{Ga}_{2} \mathrm{O}_{3}$ decrease and the peaks to assigned to $\mathrm{GaN}$ increase. In the case of the samples calcined above $800^{\circ} \mathrm{C}$, there are no detectable peaks other than the peaks assigned to GaN. It is inferred from this observation that $\mathrm{GaN}$ is synthesized 


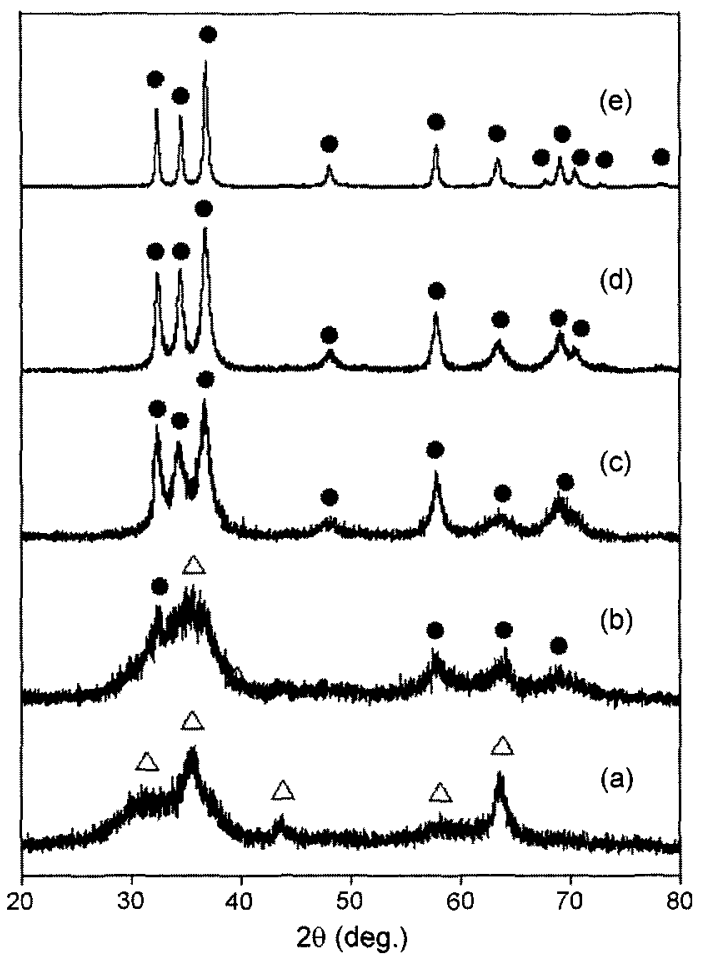

Fig. 1. XRD patterns of powders obtained by calcination of $\mathrm{Ga}_{2}\left(\mathrm{SO}_{4}\right)_{3} \cdot \mathrm{xH}_{2} \mathrm{O}$ in flowing ammonia at various temperatures for $3 \mathrm{~h}:$ (a) $600^{\circ} \mathrm{C}$, (b) $700^{\circ} \mathrm{C}$, (c) $800^{\circ} \mathrm{C}$, (d) $900^{\circ} \mathrm{C}$, and (e) $1000^{\circ} \mathrm{C}$. $\bullet \mathrm{GaN} ; \Delta, \gamma-\mathrm{Ga}_{2} \mathrm{O}_{3}$.

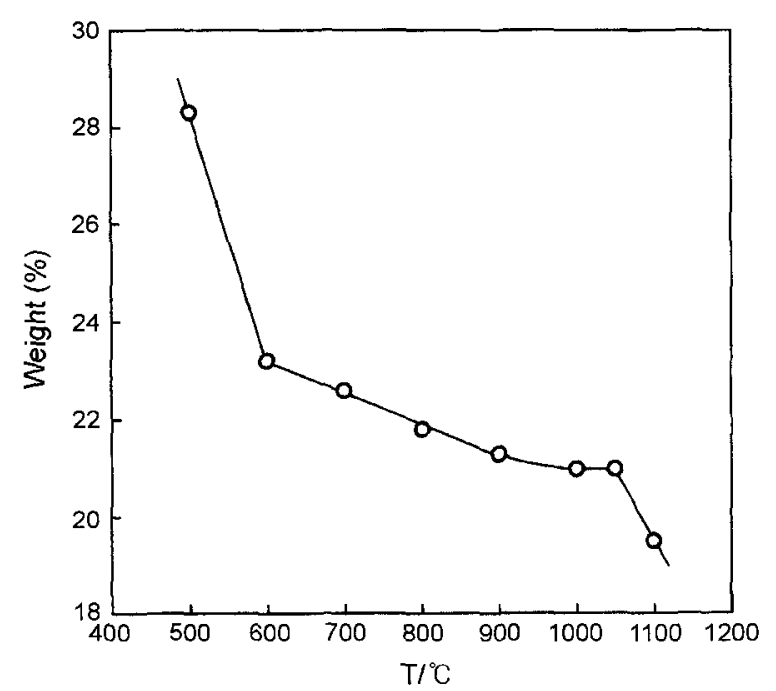

Fig. 2. Variation in weight $\%$ of $\mathrm{Ga}_{2}\left(\mathrm{SO}_{4}\right)_{3} \cdot \mathrm{xH}_{2} \mathrm{O}$ as a function of calcination temperature for $3 \mathrm{~h}$.

directly from $\gamma-\mathrm{Ga}_{2} \mathrm{O}_{3}$ without phase transition from $\gamma$ - to $\beta$ $\mathrm{Ga}_{2} \mathrm{O}_{3}$, as in the case of synthesis of $\mathrm{GaN}$ from a gallium(III) nitrate salt. ${ }^{6)}$ It is noted that gallium (III) sulfate converted to the most stable form of $\mathrm{Ga}_{2} \mathrm{O}_{3}$, i.e., $\beta-\mathrm{Ga}_{2} \mathrm{O}_{3}$ above $700^{\circ} \mathrm{C}$ under a flow of nitrogen. ${ }^{8)}$ The diffraction peaks of $\mathrm{GaN}$ powders have more narrow for gallium(IIII) sulfate than for gallium(III) nitrate, suggesting that GaN powders are higher in crystallinity for gallium(IIII) sulfate than for gallium(III) nitrate.
The conversion of a gallium(III) sulfate salt to $\mathrm{GaN}$ in flowing ammonia is accompanied by weight loss. Fig. 2 shows the change in sample weight against reaction temperature. As in the case of gallium(III) nitrate, ${ }^{6)}$ variation in the weight \% (which is defined by $100 \mathrm{x}$ weight of the product/weight of gallium(III) sulfate used) with increasing temperature is divided into four segments. The first one is below $600^{\circ} \mathrm{C}$, where the salt decomposes to $\gamma-\mathrm{Ga}_{2} \mathrm{O}_{3}$. The second one is between 600 and $950^{\circ} \mathrm{C}$, where $\gamma-\mathrm{Ga}_{2} \mathrm{O}_{3}$ converts to $\mathrm{GaN}$. The third one between 950 and $1050^{\circ} \mathrm{C}$ is almost a plateau, where $\mathrm{GaN}$ powders become crystalline and denser. The last one is above $1050^{\circ} \mathrm{C}$, where $\mathrm{GaN}$ powders sublime and/or decompose. The color of $\mathrm{GaN}$ powders changed from yellow to yellowish-gray on their decomposition. The value of $\mathrm{x}$ in $\mathrm{Ga}_{2}\left(\mathrm{SO}_{4}\right)_{3} \cdot \mathrm{xH}_{2} \mathrm{O}$ used in this study was determined to be ca. 20 from the weight $\%$ of the sample obtained at $1000^{\circ} \mathrm{C}$, assuming that the sample is a single phase of $\mathrm{GaN}$.

Crystals of $\mathrm{Ga}_{2}\left(\mathrm{SO}_{4}\right)_{3} \cdot \mathrm{xH}_{2} \mathrm{O}$ lose water in stages, yielding $\mathrm{Ga}_{2}\left(\mathrm{SO}_{4}\right)_{3}$ above $165^{\circ} \mathrm{C}$. $^{9)}$ The latter anhydrous salt decomposed to $\mathrm{Ga}_{2} \mathrm{O}_{3}$ at $c a .700^{\circ} \mathrm{C}$ under a flow of nitrogen. The fact that the weight $\%$ below $700^{\circ} \mathrm{C}$ was much lower in flowing ammonia than that in flowing nitrogen (for example, $23.2 \%$ vs. $52.3 \%$ at $600^{\circ} \mathrm{C}$ and $22.6 \%$ vs. $23.8 \%$ at $700^{\circ} \mathrm{C}$ ) indicates that the sulfate ions in the anhydrous salt react with ammonia. The product of the reaction was found at outlet of alumina tube and was identified as $\left(\mathrm{NH}_{4}\right)_{2} \mathrm{SO}_{4}$ by XRD.

The reaction between $\mathrm{Ga}_{2} \mathrm{O}_{3}$ and ammonia is expressed as follows:

$$
\mathrm{Ga}_{2} \mathrm{O}_{3}(\mathrm{~s})+2 \mathrm{NH}_{3}(\mathrm{~g}) \rightarrow 2 \mathrm{GaN}(\mathrm{s})+3 \mathrm{H}_{2} \mathrm{O}(\mathrm{g})
$$

Despite the apparent simplicity of the reaction, its detailed reaction mechanism is still unknown. Balkas and Davis showed that on the basis of the thermodynamic calculations, the reaction will not occur at temperatures where $\mathrm{GaN}$ production is feasible and suggested that the reaction intermediate is likely to be gallium( $\mathrm{I})$ suboxide $\left(\mathrm{Ga}_{2} \mathrm{O}\right){ }^{47}$ It is supposed, however, in a previous paper ${ }^{10)}$ that the conversion of $\beta-\mathrm{Ga}_{2} \mathrm{O}_{3}$ to $\mathrm{GaN}$ does not proceed through $\mathrm{Ga}_{2} \mathrm{O}$ but stepwise via amorphous gallium oxynitrides $\left(\mathrm{GaO}_{\mathrm{x}} \mathrm{N}_{\mathrm{y}}\right)$ intermediates. As the nitridation proceeds, the oxygen content in the intermediates gradually decreases, leading to the complete conversion to $\mathrm{GaN}$. The mechanism involving $\mathrm{GaO}_{\mathrm{x}} \mathrm{N}_{\mathrm{y}}$ intermediates is also valid for this reaction system. Fig. 1 shows that the samples obtained above $800^{\circ} \mathrm{C}$ are a single phase of $\mathrm{GaN}$, whereas Fig. 2 shows that the samples obtained between 600 and $950^{\circ} \mathrm{C}$ are not a single phase of $\mathrm{GaN}$. This discrepancy is well explained by existence of the amorphous $\mathrm{GaO}_{\mathrm{x}} \mathrm{N}_{\mathrm{y}}$ intermediates in the samples between 600 and $950^{\circ} \mathrm{C}$. The intermediates will not be detected by XRD because of their lack of crystallinity and turn into GaN with decrease in weight \%. The mechanism involving $\mathrm{GaO}_{\mathrm{x}} \mathrm{N}_{\mathrm{y}}$ intermediates in conversion of $\mathrm{Ga}_{2} \mathrm{O}_{3}$ to $\mathrm{GaN}$ is very similar with that involving $\mathrm{AlO}_{\mathrm{x}} \mathrm{N}_{\mathrm{y}}$ intermediates in the carbothermal reduction and nitridation of $\mathrm{Al}_{2} \mathrm{O}_{3}$ to $\mathrm{AlN}{ }^{11)}$ 


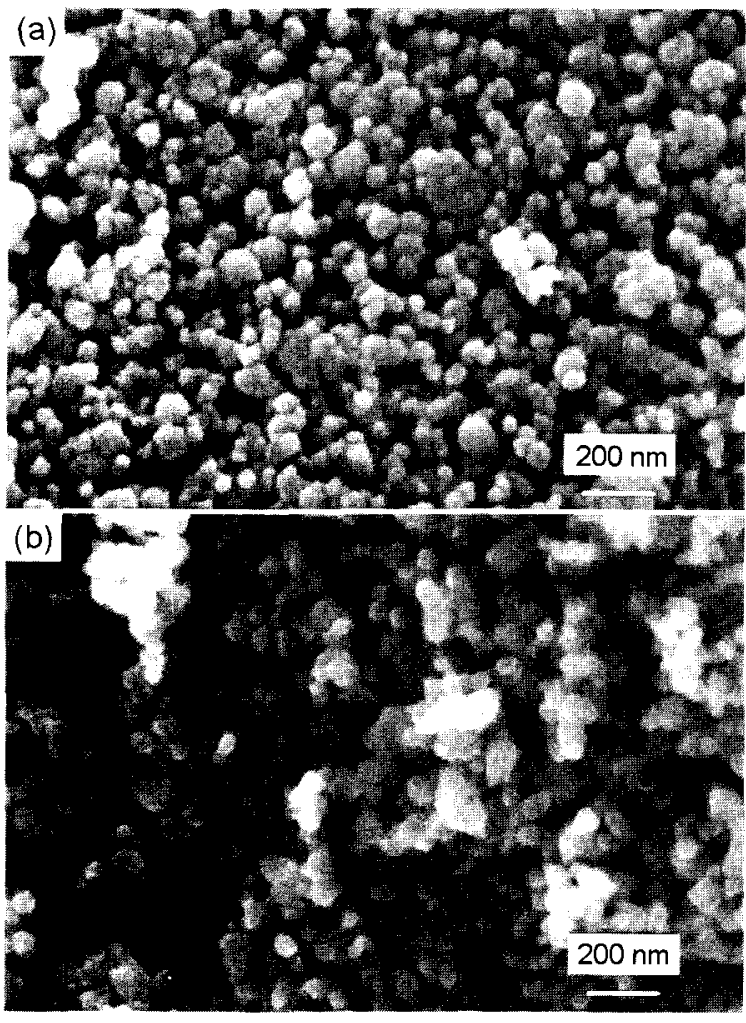

Fig. 3. SEM micrographs of powders obtained by calcining $\mathrm{Ga}_{2}\left(\mathrm{SO}_{4}\right)_{3} \cdot \mathrm{xH}_{2} \mathrm{O}$ at 600 (a) and $1000^{\circ} \mathrm{C}$ (b) for $3 \mathrm{~h}$ in flowing ammonia.

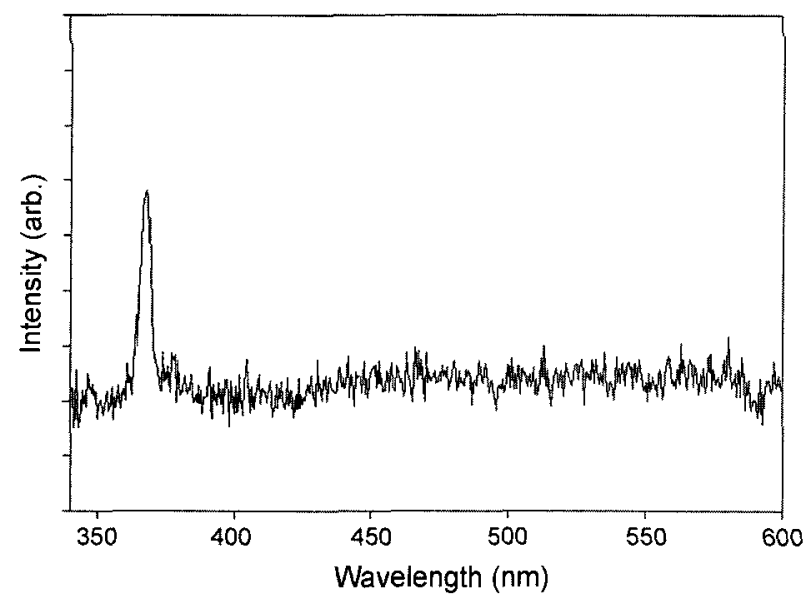

Fig. 4. Room-temperature PL spectrum of the powder obtained by calcination of $\mathrm{Ga}_{2}\left(\mathrm{SO}_{4}\right)_{3} \cdot \mathrm{xH}_{2} \mathrm{O}$ at $1000^{\circ} \mathrm{C}$ for $3 \mathrm{~h}$ in flowing ammonia.

The morphology of powders $\left(\gamma-\mathrm{Ga}_{2} \mathrm{O}_{3}\right.$ and $\left.\mathrm{GaN}\right)$ obtained at 600 and $1000^{\circ} \mathrm{C}$ was observed by SEM. The former powders (Fig. 3(a)) are agglomerated with homogeneous primary particles, the diameter of which is $c a .50 \mathrm{~nm}$. The morphology of the latter powders (Fig. 3(b)) is very similar with that of the former powder. This retention in morphology indicates that $\gamma-\mathrm{Ga}_{2} \mathrm{O}_{3}$ converts to $\mathrm{GaN}$ stepwise via $\mathrm{GaO}_{x} \mathrm{~N}_{\mathrm{y}}$ intermediates, as mentioned above.

The $\mathrm{PL}$ spectrum of $\mathrm{GaN}$ powders obtained at $1000^{\circ} \mathrm{C}$ is shown in Fig. 4. The band edge of GaN with the wurtzite structure is observed at $363 \mathrm{~nm}$, but the yellow band around $580 \mathrm{~nm}$ is not observed. GaN is apt to be nitrogen deficient in its high-temperature synthetic process, leading to occurrence of the yellow band. Using gallium(III) nitrate ${ }^{6)}$ and $\alpha$ $\mathrm{Ga}_{2} \mathrm{~S}_{3}{ }^{12)}$ as a precursor, the nitrogen deficiency in GaN was found for samples calcined above 900 and $1000^{\circ} \mathrm{C}$, respectively. No observation of the yellow band for GaN powders obtained in this study may be ascribed to their high crystallinity.

\section{Conclusions}

One of readily available Ga sources, gallium(III) sulfate is proved to a candidate precursor for $\mathrm{GaN}$ powders with high purity and single phase. The process of conversion of the salt to GaN in flowing ammonia was monitored by XRD. The salt decomposed to $\gamma-\mathrm{Ga}_{2} \mathrm{O}_{3}$ and then converted to $\mathrm{GaN}$ without $\gamma-\beta \mathrm{Ga}_{2} \mathrm{O}_{3}$ phase transition. A close examination of XRD patterns, weight loss, and SEM suggests that the conversion of $\gamma-\mathrm{Ga}_{2} \mathrm{O}_{3}$ to $\mathrm{GaN}$ does not proceed through $\mathrm{Ga}_{2} \mathrm{O}$ but stepwise via amorphous $\mathrm{GaO}_{\mathrm{x}} \mathrm{N}_{\mathrm{y}}$ as intermediates. Room-temperature PL spectra show that high-crystalline $\mathrm{GaN}$ powders obtained have the emission band at $363 \mathrm{~nm}$ and are not nitrogen deficient on calcination at high temperature of $1000^{\circ} \mathrm{C}$.

\section{Acknowledgements}

This work was supported by grant No. R05-2001-00841 from the Basic Research Program of the Korea Science \& Engineering Foundation. The XRD patterns were recorded at the Yeungnam University Instrumental Analysis.

\section{REFERENCES}

1. O. Ambacher, "Growth and Applications of Group IIINitrides," J. Phys. D: Appl. Phys., 31 2653-710 (1998).

2. S. Sakai, S. Kurai, T. Abe, and Y. Naoi, "Photopumped Stimulated Emission from Homoepitaxial GaN Grown on Bulks GaN Prepared by Sublimation Method," Jpn. J. Appl. Phys., 35 L77-9 (1996).

3. S. Porowski, "High Pressure Growth of GaN-new Prospect for Blue Laser," J. Cryst. Growth, 166 583-89 (1996).

4. C. M. Balkas and R. F. Davis, "Synthesis Routes and Characterization of High-purity, Single-phase Gallium Nitride Powders," J. Am. Ceram. Soc., 79 [9] 2309-12 (1996).

5. S. Lee, I. Y. Park, and S. Kim, "New Simple Synthesis Route of GaN Powders from Gallium Oxyhydroxide," Mater. Sci. Eng., B95 275-78 (2002).

6. W.-S. Jung, "Preparation of Gallium Nitride Powders and Nanowires from a Gallium(III) Nitrate Salt in Flowing Ammonia," Bull. Kor. Chem. Soc., in press.

7. Joint Committee on Powder Diffraction Standards (JCPDS) Card No. 20-0426.

8. W.-S. Jung, Unpublished results.

9. M. J. Taylor, "Aluminum and Gallium," pp. 135 in Compre- 
hensive Coordination Chemistry, Vol. 3. Ed. by G. Wilkinson, Pergamon Press, Oxoford, 1987.

10. W.-S. Jung, "Reaction Intermediate(s) in the Conversion of $\beta$-gallium Oxide to Gallium Nitride Under a Flow of Ammonia," Mater. Lett., 57 [1] 110-14 (2002).

11. W.-S. Jung, "Synthesis of Aluminum Nitride Powders and
Whiskers from $\left(\mathrm{NH}_{4}\right)[\mathrm{Al}($ edta $)] \cdot 2 \mathrm{H}_{2} \mathrm{O}$ Complex Under a Flow of Nitrogen," J. Kor. Ceram. Soc., 39 [3] 272-77 (2002).

12. W.-S. Jung, C. Park, and S. Han, "Probing the Nitrogen Deficiency in Gallium Nitride by ${ }^{71} \mathrm{Ga}$ Magic-angle Spinning NMR Spectroscopy," Bull. Kor. Chem. Soc., 24 [7] 1011-13 (2003). 